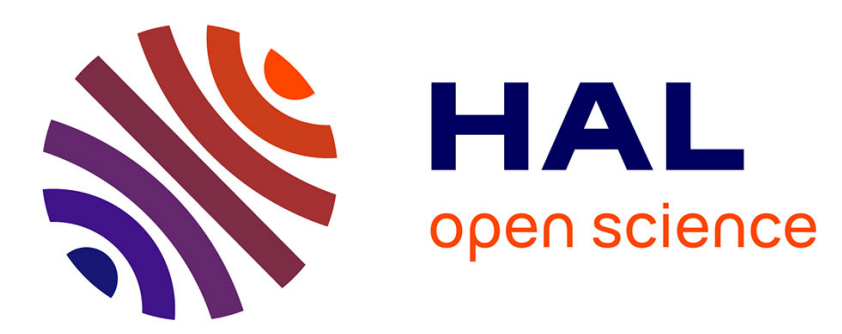

\title{
Service-based Negotiation for Advanced Collaboration in Enterprise Networks
}

Carlos Coutinho, Adina Cretan, Catarina Ferreira da Silva, Parisa Ghodous, Ricardo Jardim-Gonçalves

\section{- To cite this version:}

Carlos Coutinho, Adina Cretan, Catarina Ferreira da Silva, Parisa Ghodous, Ricardo JardimGonçalves. Service-based Negotiation for Advanced Collaboration in Enterprise Networks. Journal of Intelligent Manufacturing, 2016, 27 (1), pp.201-216. 10.1007/s10845-013-0857-4 . hal-01270638

\section{HAL Id: hal-01270638 \\ https://hal.science/hal-01270638}

Submitted on 22 Dec 2019

HAL is a multi-disciplinary open access archive for the deposit and dissemination of scientific research documents, whether they are published or not. The documents may come from teaching and research institutions in France or abroad, or from public or private research centers.
L'archive ouverte pluridisciplinaire HAL, est destinée au dépôt et à la diffusion de documents scientifiques de niveau recherche, publiés ou non, émanant des établissements d'enseignement et de recherche français ou étrangers, des laboratoires publics ou privés. 


\section{Service-based negotiation for advanced collaboration in enterprise networks}

\section{Carlos Coutinho, Adina Cretan, Catarina Ferreira da Silva, Parisa Ghodous \& Ricardo Jardim-Goncalves}

Journal of Intelligent Manufacturing

ISSN 0956-5515

Volume 27

Number 1

J Intell Manuf (2016) 27:201-216

DOI 10.1007/s10845-013-0857-4

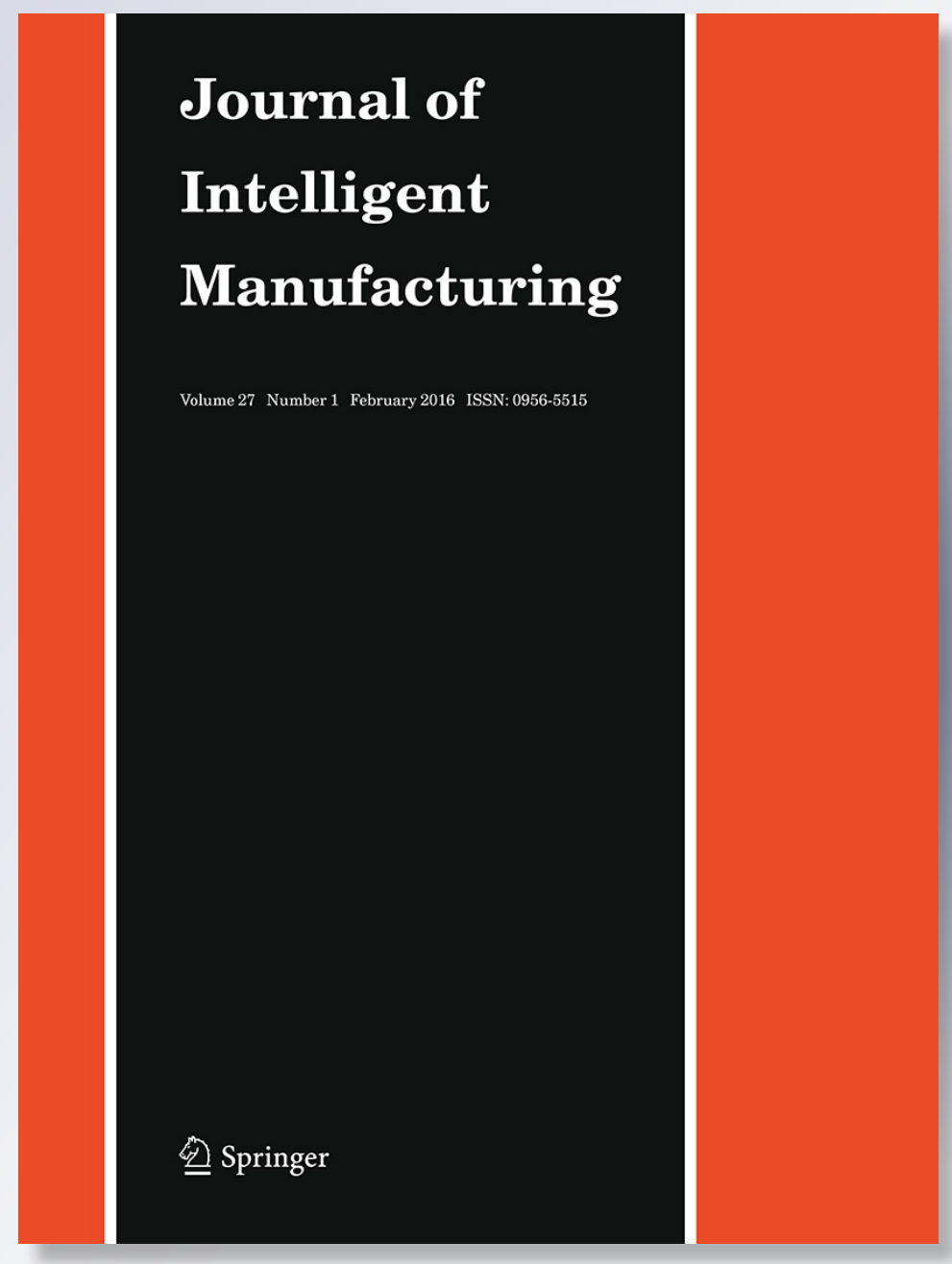

Springer 
Your article is protected by copyright and all rights are held exclusively by Springer Science +Business Media New York. This e-offprint is for personal use only and shall not be selfarchived in electronic repositories. If you wish to self-archive your article, please use the accepted manuscript version for posting on your own website. You may further deposit the accepted manuscript version in any repository, provided it is only made publicly available 12 months after official publication or later and provided acknowledgement is given to the original source of publication and a link is inserted to the published article on Springer's website. The link must be accompanied by the following text: "The final publication is available at link.springer.com". 


\title{
Service-based negotiation for advanced collaboration in enterprise networks
}

\author{
Carlos Coutinho - Adina Cretan - Catarina Ferreira da Silva • \\ Parisa Ghodous · Ricardo Jardim-Goncalves
}

Received: 23 July 2013 / Accepted: 13 December 2013 / Published online: 7 January 2014

(C) Springer Science+Business Media New York 2014

\begin{abstract}
Information systems support organisations to achieve greater efficiency by automating their activities. Nowadays, in the actual competitive and global business context, the advent of enterprise networking has been challenging collaboration, coordination and continuous interactions among dissimilar information systems to adapt and improve them. Sustainability of interoperability among heterogeneous systems regarding sharing information and knowledge in a collaborative dynamic environment is hard to achieve and maintain. This paper proposes a service-based negotiation framework for advanced collaboration in enterprise networks, as a solution to improve the sustainability of interoperability within enterprise information systems. Validation in industrial scenario is presented and discussed.
\end{abstract}

Keywords Enterprise interoperability · Ontology · Conflict resolution · Negotiation · Cloud computing · Enterprise information systems (EIS)

C. Coutinho $(\varangle)$

Caixa Mágica Software, Lisbon 1600-196, Portugal

e-mail: carlos.coutinho.phd@gmail.com

A. Cretan

Computer Science Department, "Nicolae Titulescu" University

of Bucharest, 031046 Bucharest, Romania

C. F. da Silva · P. Ghodous

Lyon Research Centre for Images and Intelligent Information

Systems, Claude Bernard Lyon 1 University,

69100 Villeurbanne, France

R. Jardim-Goncalves

Faculty of Sciences and Technology, UNINOVA, New University

of Lisbon, 2829-516 Caparica, Portugal

\section{Introduction}

The advent of the Internet and of the cloud-computing trend have led to the development of various forms of virtual collaboration in which the organizations are trying to exploit the facilities of the network to achieve higher utilization of their resources. In this collaborative networked environment, enterprises are developing business areas dedicated to the purpose of finding and complying with the best set of partners and suppliers for solutions that are aligned with the enterprise's strategy. Enterprise integration, interoperability and networking are some of the major disciplines that are enabling companies to improve collaboration and communication in the most effective way (Panetto and Cecil 2013).

To be able to perform, enterprises need to exchange information, whether this exchange is internal (among departments of the enterprise), external (among the enterprise or part of it and an external party), or both. Enterprise Interoperability (EI) is thus defined as the ability of an enterprise to seamlessly exchange information in all the above cases, ensuring the understanding of the exchanged information in the same way by all the involved parties (Li et al. 2006). Large enterprises accomplish this by setting market standards and leading their supply chain to comply with these standards. Small and Medium Enterprises (SMEs) usually don't have the empowerment to do so, and are therefore more sensible to the oscillations of the environment that involves them, which leads them to the need to constantly change to interoperate with their surrounding ecosystem. Sustainable EI (SEI) is thus defined as the ability of maintaining and enduring the interoperability along the enterprise systems and applications' life cycle. Achieving a SEI in this context requires a continuous maintenance and iterative effort to adapt to new conditions and partners, and a constant check of the status and 
maintaining existing interoperabilities (Jardim-Goncalves et al. 2010).

EI concerns alignment or common understanding in various forms and levels, from middleware (e.g., signalling, interfaces, and platforms) to semantics (e.g., concepts, taxonomies, and relationships), workflows and methodologies, solutions and business visions. EI can be challenged either because a new enterprise which joined the ecosystem introduces new conditions, or because one of the existing enterprises has made a change in the existing interoperable environment.

As the number of enterprises in the ecosystem grows and interoperability becomes more complex, any change may result in the loss of the interoperable environment and therefore to a "downtime" period where there is no business. When trying to regain interoperability, e.g., due to a new concept, an enterprise may decide to establish a particular peer-topeer interoperable hub (e.g., translator, adapter) and isolate it from the others, or it may decide to adopt the new concept. The first option has the disadvantage of allowing the coexistence of different concepts in the same enterprise, which will end up in problems e.g., due to reuse and team rotation. The latter option has the danger of triggering a chain-reaction of changes in the network until all of them adopt the new concept, which may be desirable or not.

The main issue is that the number of options and decisions towards interoperability that need to be taken is escalating in number and importance, and these decisions have and increasing influence on the evolution of the enterprise business. This paper recommends negotiations as the proper way to resolve these discrepancies. Negotiations allow a proper formalisation of the SWOT (strengths, weaknesses, opportunities and threats), while presenting the various alternative solutions. It also enables a clear definition of criteria (e.g., impact, downtime, cost, alignment with enterprise strategy, new markets) for the selection of a particular solution, providing a strong justification for reaching mature choices.

Negotiations are sets of complex actions (e.g., creation of a new proposal, evaluation of proposals by acceptance or rejection), some of which may occur in parallel. In a negotiation, multiple participants exchange and take decisions in multiple phases over a set of multiple attributes of the negotiation objects (e.g., price, size, quality). In order to formalise and model the negotiation processes, the metaphor of Interaction Abstract Machines (IAMs) is adopted (Cretan et al. 2012a). This approach allows the modelling of the evolution of multiple negotiation phases in parallel and including non-deterministic aspects.

The negotiation process towards interoperability needs to be supported by a flexible and consistent set of collaboration tools. A major improvement in the last decade on this field was achieved by the development of Service-Oriented
Architectures (SOA) (Relvas et al. 2008). Web Services have reshaped the existing concepts of solution deployment and provisioning, and paved the way for other important concepts using the same paradigm, like functional discovery and subscription in common repositories, orchestration and composition of services into more complex ones (Coutinho et al. 2012), thus creating highly modular and flexible solutions as required.

While SOA is meaningful in terms of solutions flexibility, it has limitations with respect to deployment. The advent of distributed computing complements SOA to deal with scalability issues, and the emergent cloud-based solutions are the exponent of this development.

This paper proposes a framework that offers negotiation mechanisms to support the sustainability of interoperability in business-to-business interactions, in networked enterprise environments. Additionally, the presented approach tackles the issue of semantic heterogeneity of such an environment by introducing ontologies as the main support in the negotiation process. "Problem space and research challenges" section describes the problem space and the research challenges concerning the described problem. "Literature review" section presents the theoretical background used on this research. "Collaborative negotiation framework" section proposes the collaborative negotiation framework in the context of EI, and "Negotiation coordination model" section describes the negotiation coordination model. "Methodology-based negotiation for sustainability of EI" section presents the proposed methodology for sustainability of EI, while "Business case scenario for framework validation" section analyses the application of the proposed methodology into a real business case scenario. Finally, "Conclusions and future work" section presents the conclusions and final considerations.

\section{Problem space and research challenges}

The idea presented in this paper is to achieve and to maintain the interoperability not by imposing a new model but by negotiating any change that may occur in the collaborative networked environment within the existing interoperable partners or with the new player towards reaching a better solution. This approach leads to improved solutions for interoperability, standards and best-practices that will benefit all players.

According to the presented approach regarding the negotiation, the participants to a negotiation may propose offers and each participant may decide in an autonomous manner to stop a negotiation either by accepting or by rejecting the received offer. Also, depending on its role in a negotiation (e.g., initiator or guest) a participant may invite new participants in the negotiation process. 
For example, we can consider a scenario of distributed autonomous SMEs acting in a furniture sector in a collaborative networked environment. Each SME autonomously manages its contracts, schedules and resources but in order to meet the challenges of a big contract, all the enterprises are willing to cooperate.

However, in this dynamic environment, one of the partners has to leave the network (e.g., due to the change of activity). This change in the system affects all the network partners. Additionally, the departure of a partner will have a strong impact on ongoing contract. Thus, in order to maintain the interoperability of the system, the remaining job must be negotiated among the remaining partners or a new partner may be involved.

The business-to-business interaction context in which these negotiations take place forces us to model the unexpected and the dynamic aspects of this environment. An organization may participate in several parallel negotiations. Each negotiation may end with the acceptance of a contract that will automatically reduce the available resources and it will modify the context for the remaining negotiations. We have modelled this dynamic evolution of the context using the metaphor of Interaction Abstract Machines (IAMs) that allows us to limit the acceptance of a negotiation to the available set of resources (Cretan et al. 2012b).

\section{Literature review}

Ensuring sustainable interoperability among organizations in a networked environment is a crucial factor in order to successfully manage collaborations at all levels: abstract (business); concrete (technology), including

- informational (information vs. data);

- functional (activity vs. service);

- and behavioural (process vs. workflow).

Outlining the crucial position of information systems (IS) inside an organisation, Benaben et al. (2013) state that the main issue is to ensure that the IS of the partners involved in the collaboration are able to work together to constitute a coherent and homogeneous set of IS - the IS of the collaborative situation. To address this issue, Benaben et al. (2013) and Benaben and Pingaud (2010) propose the Mediation Information System Engineering Project (MISE Project) which aims at providing collaborating organizations with a mediation information system (MIS) able to support the interoperability of a collaborative network. The project takes a modeldriven approach to develop a complete MIS design method, taking into account the semantic reconciliation between business and technical levels.

In the same area, Coutinho et al. (2012) define a framework to support Sustainable Interoperability using Model-
Driven Architectures (MDA), Model-Driven Interoperability (MDI), Service-Oriented Architectures (SOA) and Ontologies. This framework allows businesses to build higher interknowledge to achieve stronger interoperability. Agostinho et al. (2011) propose a framework which applies MDA transformations to data models to maintain an interoperable peer-topeer $(\mathrm{P} 2 \mathrm{P})$ connection between two applications. According to Panetto (2007) the Model Driven Interoperability (MDI) is considered a major methodology for achieving Enterprise Interoperability (EI), adopting MDA layers for the development of a model-morphism that implements the transformations among different enterprise models in the deployment of interoperable enterprise systems.

Jardim-Goncalves et al. (2012) state that interoperability issues have arisen when using instances of meta-models from different sources, and identify semantic annotation, ontology harmonization, and merging as examples of important methods for the Enterprise Interoperability Science Base (EISB).

An enterprise information system is generally composed of a multitude of applications able to answer certain enterprise needs. Izza (2009) considers the integration of enterprise information systems a crucial problem due to the applications composing the information systems of the companies that increasingly require working together. The author states that the heterogeneity of enterprise applications is the major challenge of the integration problem due to the multiple technical, syntactical and semantic conflicts that concern these applications. This requires a mediation process to deal with these differences.

Many research papers (Dutra et al. 2010) take the approach of using ontologies to address the semantic integration and interoperability issues, to deal with the semantic heterogeneity of such an environment. Zdravković et al. (2011) takes the approach of semantic enrichment of the Supply Chain Operations Reference (SCOR) model using Web Ontology Language (OWL), enabling effective knowledge management in supply chain networks and facilitating the semantic interoperability of systems.

To support the continuous evolution of ontologies, Khattak et al. (2011) propose to re-establish the mappings among dynamic ontologies by using the changing history of ontology. This has the benefit of reducing the time required for reconciling mappings among ontologies, compared to already existing systems that completely reinitiate the process.

Also, ontologies play an important role in the development of Multi-Agent Systems (MAS) for the semantic web due to the heterogeneity of agents. Thus, Laclavík et al. (2006) state that the lack of the interconnection with semantic web standards such as OWL is the main disadvantage of MAS. In this respect, the authors develop a semantic knowledge agent model that can be used in an agent-based application where such interconnection is needed. 
The issue of using a common ontology has been approached in many works, such as the one of Torres and Wijnands (2011). Although beneficial in many ways, the use of a common ontology becomes much more complex when it deals with multiple application fields in what regards creation, updates and efficient structure. In this respect, Sarraipa et al. (2010b) present MENTOR methodology based on the mediator ontology concept which assists the semantic transformation among each organization's ontology and the referential one. Additionally, the authors (Sarraipa et al. 2010a) propose to use MENTOR as the collaborative ontologybuilding methodology, enriched with Qualitative Information Collection Methods (QICM), in order to improve the approach to elicit knowledge from business domain experts.

The increasing exchange of knowledge, resources and expertise among virtual organisations in a collaborative environment has led to many conflicting situations. For solving the conflicts, different kinds of research approaches have been applied, from automatic resolution (Haya et al. 2006) to mediated resolution approach (Shin et al. 2007). Later works (Shin et al. 2008, 2010) combine automatic resolution with social mediation for resolving conflicts among users. According to the authors, the automatic resolution approach is used when the decision is simple or close to what all users expects, while the social mediation involves negotiating a resolution, and is performed by recommending possible candidates. It is used when the decision is complex or different from what at least one of the users expects.

The negotiation approach plays a key role in solving the conflicts that may occur in a collaborative dynamic environment (Oliveira and Camarinha-Matos 2012). However, the inadaptability of agents to evolving negotiation protocols, and the ambiguity of the agents' negotiation term are the main issues that can arise during agent interactions (Dong et al. 2008; Mazuel and Sabouret 2009). Thus, semantic interoperability is an important issue in a networked enterprise (Jeon et al. 2011). The same idea of using of ontologies technology in order to settle the knowledge conflicts and to solve semantic ambiguity has been extended into the field of automated negotiation research (Chen et al. 2012). In this regard, Wang et al. (2011b) propose an ontology-based knowledge representation approach to provide a semantic interoperable environment to realize automatic negotiations in a virtual collaborative environment.

The final goal of the negotiation process consists in reaching a common agreement among parties in order to support possible collaborations. In this respect, Oliva et al. (2010) propose a framework, called SANA (Supporting Artefacts for Negotiation with Argumentation), that incorporates intelligent components able to mediate the agents participating in negotiation to reach an agreement by inferring mutuallyacceptable proposals. This solution of using an artificial intel- ligent mediator can be found in other researches on argumentation based-negotiation, particularly in systems designed for public deliberation (Ahmadi and Charkari 2010; Tolchinsky et al. 2011). Although beneficial in many ways, the approach of using an intelligent mediator for guiding the participating agents in the decision-making process would limit the autonomy of participants while increasing the power of the mediator. In the later work, (Ahmadi et al. 2011) the proposed e-negotiation system solves the problem of multi-issue negotiations. In addition, the system is based on the multi-agent systems approach in which agents can make autonomous negotiation decisions.

Many recent papers describe the advantages of using negotiation in cloud computing. Thus, Pan (2011) states that the main issue for cloud computing in order to support negotiation is to establish the Service Level Agreement (SLA) between service providers and consumers and proposes a software agent based automated service negotiation framework for on-demand cloud service provision; Wang et al. (2011a) provide a SLA platform in order to help cloud consumers to select most reliable cloud providers and make negotiation process more equitable and convenient; Groléat and Pouyllau (2011) tackled the end-to-end SLA negotiation problem by optimizing long-term revenues of domains while processing dynamically customers' requests.

Russ and Walz (2012) propose a multi agent supply chain simulation framework (MACSIMA) that allows the design of large-scale supply network topologies. These are formed by a multitude of autonomous agents that act on behalf of the companies they represent in the supply network. The result of the proposed solution shows that the use of negotiating agents for coordinating a supply network is conditional on the fine tuning of the parameters of the learning mechanism of the agents in order to reach an optimal coordination outcome. The setting of the parameters of the learning mechanism leads to a significant variation of the overall profit and turnover of a supply network. MACSIMA provides all agents with negotiation and learning capabilities that allow the evaluation and simulation of the joint evolution of the price negotiation strategies of the business agents that exchange goods over an electronic business-to-business (B2B) market.

Luo et al. (2012) develop a template based knowledge engineering methodology for building automated negotiation systems. The proposed template consists primarily of a generic knowledge model of a main task and a library of modular and reusable templates of subtasks. The different combination of templates can constitute different automated negotiation models.

Jazayeriy et al. (2011) provide a review on the progress of soft-computing (SC) techniques used in e-negotiation. Their approach is based on the idea that using a combination of soft computing techniques, such as: Fuzzy Logic (FL), Neural networks (NN), Genetic algorithm (GA) and Probabilistic 
reasoning (PR) can decrease the complexity of negotiation making it closer to real world negotiation.

Relating to the same idea of constructing a more humanlike agent model, Cao (2012) describes a generic decisionmaking model based on the Belief-Desire-Intention (BDI) agent architecture. The negotiation decision-making model proposed can support dynamic selection of the negotiation strategies during the negotiation process. The proposed model can fill the gap between the theory development and the implementation of the negotiation support model.

One problem that could be caused by the constant use of negotiations through interoperability is the existence of deadlocks. Several approaches have been proposed in the literature to solve this problem. Qing and Chun (2003) stated that negotiation deadlock on a single issue may occur in multiissue negotiation when agents cannot make a compromise on one of issues. Their strategy for avoiding the deadlock is based on an optimization algorithm for reservation value of multiple issues in bilateral negotiations by using a Reinforcement Learning algorithm which broadens the reserved value of the negotiation and narrows other irrelevant issues. Other approaches tackle the issue of negotiation deadlock by introducing a mediator in the negotiation process such as the proposal of Lin and Chou (2003). They introduce a mediation mechanism to break the deadlock by supervision from the third party. Other later works, such as Yang et al. (2010), solve this problem occurring in negotiations without time limit by using an optimization strategy based on a learning method to estimate opponent's weight of their negotiation issue in order to give them full consideration to the issue dependencies.

Related to same area of collaboration processes, conflict prevention and deadlock-free, Huan and Lili (2010) provide a model of dynamic task allocation among multiple agents based on Contractor Network Protocol (CNP) while Liu et al. (2008) present a prototype system of conflict prevention and resolution based on a video conference negotiation strategy.

\section{Collaborative negotiation framework}

The proposed Collaborative Framework offers mechanisms to support negotiations in a distributed environment. This includes a set of hierarchically layered and distributed components that implement the rules of the modelled negotiation and also handle the interoperability aspects of the negotiation, as seen on Fig. 1.

To allow a sustainable, flexible and generic approach towards the implementation of the underlying infrastructure, a Cloud web-service-based platform is proposed for this framework. Considering the current trend on services provisioning and that the complexity of the involved interactions may be from simple to very demanding, the proposed imple- mentation for it encompasses the subscription of cloud-based services for this matter (Software as a Service or SaaS). These highly flexible infrastructures and service provider platforms allow the subscription of simple or more demanding processing according to the negotiation environment needs.

The framework's top layer (Negotiation Manager) is targeted to the Manager of each negotiation party. It handles all business decisions (Cretan 2011) that need to be taken (e.g., proposal, acceptance of proposal, rejection of proposal, invite of another party to take part in the negotiation process) and analyses and manages the negotiated parameters, communicating with the lower layers using web-services (Relvas et al. 2008).

A second layer is dedicated to the Coordination Services (CS) which assist the negotiations at a global level (negotiations with different participants on different jobs) and at a specific level (negotiation on the same job with different participants) handling all issues regarding communication at this layer level (synchronisation among the CS of the several parties that are taking place in the negotiation). The CS shall also handle the on-going transactions and manage the persistence for the status of the negotiation sequences. To improve the interoperability, data shall be exchanged using the standard protocol ISO10303 STEP (Jardim-Goncalves et al. 2006, 2007). This layer is also responsible for handling semantic discrepancies between the negotiating parties via the use of one or more ontologies (Sarraipa et al. 2008). It may also include an agent-based architecture (Luo et al. 2012) to support the complexities of the negotiation operations through the Middleware layer (Georgantas et al. 2011).

These middleware services shall provide support for performing all aspects related with basic infrastructure, and handling the heterogeneity related with multiple negotiation players; it may also include publication of the job requirements and characteristics, in order to allow potential companies interested in participating to "subscribe" to it and be able to enter the negotiation. The middleware layer depends on the type and size of the interaction between the players on the negotiation.

Each negotiation is organised in three main steps: initialisation; refinement of the job under negotiation; and closure (Sycara and Dai 2010). The initialisation step allows to define what has to be negotiated (Negotiation Object) and how (Negotiation Framework) (Duan et al. 2010). In the refinement step, participants exchange proposals on the negotiation object trying to satisfy their constraints (Hu and Deng 2011). Closure concludes the negotiation.

We can model different negotiation scenarios that can be found in the lifecycles of the business to business negotiations. Some of these scenarios can range from simple cases of selection of possible partners and a direct outsourcing of a job, to more complex scenarios of concurrent negotiations with multiple partners to outsource a non-divided job or con- 
Fig. 1 The architecture of the collaborative framework

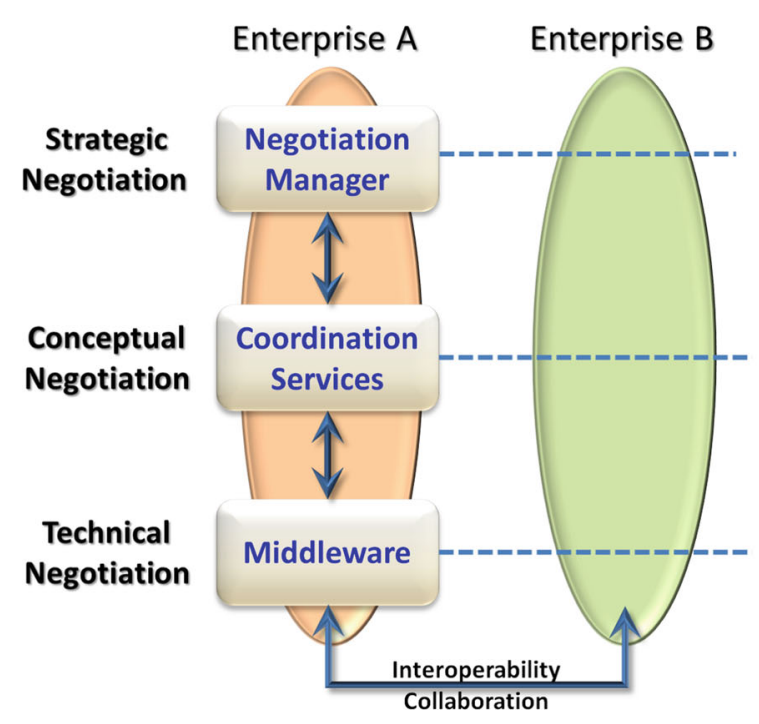

Decisions to be taken:

- Accept/Reject Proposal

- Propose Solution

- Invite new party

- Start new negotiation

Coordination:

- Transactions, Strategies

- Semantics, Ontologies

- Agents, Rules Engines

Middleware Provision:

- Heterogeneity

- Transformations

- Communication (ICT)

- Services (SOA, SaaS)

- Infrastructure (IaaS) current negotiations with the possibility to dynamically split the job during the negotiation.

\section{Negotiation coordination model}

This section proposes a formal model to settle and manage the coordination rules of one or more negotiations which can take place in parallel, by describing the basic concepts underlying the model, and the negotiation model using the metaphor of Interaction Abstract Machines (IAMs). The Program Formula is described to define the methods used to manage the parallel evolution of multiple negotiations.

\section{Basic concepts}

In this setup, at a local level, the model requires a formal description of the rules of coordination that manage the behaviour of the agent in a negotiation; at a global level, the model must provide a global coordination of all negotiations of an agent.

The fundamentals of the negotiation model are given by the following basic concepts:

A Negotiation Model is defined as a quintuple $\mathrm{M}=<\mathrm{T}, \mathrm{P}$, $\mathrm{N}, \mathrm{R}, \mathrm{O}>$ where:

- T denotes the time of the system, assumed to be discrete, linear, and uniform (Emerson 2010);

- P denotes the set of participants in the negotiation framework. The participants may be involved in one or many negotiations;

- $\mathrm{N}$ denotes the set of negotiations that take place within the negotiation framework;

- $\mathrm{R}$ denotes the set of policies of coordination of the negotiations that take place within the negotiation framework;
- O denotes the common ontology that consists of the set of definitions of the attributes that are used in a negotiation.

A negotiation is described at a time instance through a set of negotiation sequences.

Let $\mathrm{Sq}=\{\mathrm{si} \mid \mathrm{i} \in \mathbb{N}\}$ denote the set of negotiation sequences, such that $\forall \mathrm{si}, \mathrm{sj} \in \mathrm{Sq}, \mathrm{i} \neq \mathrm{j}$ implies $\mathrm{si} \neq \mathrm{sj}$. A negotiation sequence $\mathrm{si} \in \mathrm{Sq}$ such that $\mathrm{si} \in \mathrm{N}(\mathrm{t})$ is a succession of negotiation graphs that describe the negotiation $\mathrm{N}$ from the moment of its initiation and up to the time instance $t$. The negotiation graph created at a given time instance is an oriented graph in which the nodes describe the negotiation phases that are present at that time instance (i.e., the negotiation proposals sent up to that moment in terms of status and of attributes negotiated) and the edges express the precedence relationship between the negotiation phases.

The negotiation phase $(p h)$ indicates a particular stage of the negotiation under consideration.

The Status is the possible state of a negotiation. This state takes one of the following values (Status $\in$ initiated, undefined, success, failure\}):

- initiated - the negotiation, described in a sequence, has just been initiated;

- undefined-the negotiation process for the sequence under consideration is ongoing;

- success - in the negotiation process, modelled through the sequence under consideration, an agreement has been reached;

- failure-the negotiation process, modelled through the sequence under consideration, resulted in a denial.

Issues is the set of attributes with associated values that describe the proposals made in a negotiation phase.

Snapshot is the set of combinations between a negotiation aspect (Status) and the information that is negotiated (Issues). 
The functions status and issues return, respectively, the state (status) of a negotiation instance and the set of the attributes negotiated (issues) within a negotiation instance.

\section{Metaphor interaction abstract machines (IAMs)}

The metaphor Interaction Abstract Machines (IAMs) will be used to facilitate modelling of the evolution of a multi-attribute, multi-participant, multi-phase negotiation. In IAMs, a system consists of different entities and each entity is characterized by a state that is represented as a set of resources. It may evolve according to different laws of the following form, also called "methods":

A1@...@An >>-B1@...@Bm

A method is executed if the state of the entity contains all resources from the left side (called the "head") and, in this case, the entity may perform a transition to a new state where the old resources $(A l, \ldots, A n)$ are replaced by the resources $(B 1, \ldots, B m)$ on the right side (called the "body"). All other resources of the entity that do not participate in the execution of the method are present in the new state.

The operators used in a method are:

- the operator@ assembles together resources that are present in the same state of an entity;

- the operator $<>$ - indicates the transition to a new state of an entity;

- the operator \& is used in the body of a method to connect several sets of resources;

- the symbol " $T$ " is used to indicate an empty body.

In IAMs, an entity has the following characteristics:

- if there are two methods whose heads consist of two sets of distinct resources, then the methods may be executed in parallel;

- if two methods share common resources, then a single method may be executed and the selection procedure is made in a non-deterministic manner.

In IAMs, the methods may model four types of transition that may occur to an entity: transformation, cloning, destruction and communication. Through the methods of type transformation the state of an entity is simply transformed in a new state. If the state of the entity contains all the resources of the head of a transformation method, the entity performs a transition to a new state where the head resources are replaced by the body resources of the method. Through the methods of type cloning an entity is cloned in a finite number of entities that have the same state. If the state of the entity contains all the resources of a head of a cloning method and if the body of the method contains several sets of distinct resources, then the entity is cloned several times, as determined by the num- ber of distinct sets, and each of the resulting clones suffers a transformation by replacing the head of the method with the corresponding body. In the case of a destruction of the state, the entity disappears. If the state of the entity contains all the resources of the head of a transformation method and, if the body of the method is the resource $\mathrm{T}$, then the entity disappears.

In IAMs, the communication among various entities is of type broadcasting and it is represented by the symbol " "”. This symbol is used to the heads of the methods to predefine the resources involved in the broadcasting. These resources are inserted in the current entity and broadcasted to all the entities existent in the system, with the exception of the current entity. This mechanism of communication thus executes two synchronous operations:

- transformation: if all resources that are not predefined at the head of the method enter in collision, then the predefined resources are inserted in the entity and are immediately consumed through the application of the method;

- communication: insertion of the copies of the predefined resources in all entities that are present in the system at that time instance.

\section{Program formula}

In a multi-entity system, the metaphor IAMs allows the modelling and control of the autonomous evolution process for each entity in the system. Each entity may change its state independently of others, using its own resources and the methods of its computational space. This approach allows us to model in parallel the evolution of multiple negotiation phases. By using the metaphor IAMs, the evolution of the negotiation phases, associated to the nodes of a negotiation sequence, will be managed through different methods that are put together in a Program Formula $(P F)$. Program Formula of a negotiation sequence $s-P F(s)$-represents the set of the methods used to manage the evolution of the sequence s.

In our negotiation model, a negotiation phase is connected to the set of snapshots of the negotiation status and of the instants of the attributes negotiated that are present in a node of the negotiation graph. In this way, to specify not only the information regarding the negotiation state and the attributes values but also the actions that will contribute to the evolution of the negotiation, we model the nodes of a graph of the negotiation sequence as sets of particles, called negotiation atoms. Therefore, a negotiation atom, denoted atom(s, ph), is a set of resources, called particles, that describe the negotiation state in terms of the negotiation sequence $\mathrm{s}$ for the negotiation stage $p h$.

We defined in this way five types of particles: representation particles, event particles, message particles, control particles, and computational particles. 
In our negotiation model, a negotiation sequence keeps, in the nodes of the graphs, sets of snapshots, images that a participant has about the negotiation status and about the attributes that are negotiated in the current sequence as well as in all other sequences for which there is a distribution of information.

This information is modelled within the negotiation process as representation particles that are described by three parameters (Name, $S$, and I):

- Name is defined by concatenation of the identifiers of the participants with the sequence under consideration (e.g., pjsj).

- $S$ takes values in the set Status $=\{$ initiated, undefined, success, failure\}. This value corresponds to the value returned by the function status().

- I takes values in the set Issues of the negotiated attributes with the associated values. This value corresponds to the value returned by the function issues().

In this way, a representation particle of an atom, associated to a sequence $s$ for a phase $p h$, is a snapshot of the sequence $s$ for the phase $p h$. To provide a detailed description of the negotiation sequences involved in a negotiation phase, we define the following particles:

- localr(Name, S, I): local representation particle. This particle holds the local snapshot of the current sequence;

- extr(Name, $S, I)$ : external representation particle. This particle holds the external snapshot that describes the modality in which another sequence perceives the same negotiation phase;

- firstr(Name, S, I): external negotiation particle. This particle holds the external snapshot associated to the sequence that generated the current sequence.

In this way, a new node of a negotiation sequence may be described through a set of representation particles that are part of the same atom.

The particles event specify the types of transitions used by IAMs in terms of the message types that are exchanged within a negotiation.

A particle event is described by three parameters:

- Id identifies the atom to be cloned;

- New_id identifies the newly created atom;

- $M s g$ contains the negotiation message with data that will contribute to the evolution of the negotiation in the newly created atom.

To facilitate the identification of both the cloning operation and of the direction in which the new negotiation atom will evolve, we propose four particles event: clone_propose, clone_accept, clone_reject, and clone_create.
The particles clone_propose(Id, New_id, Msg), clone_ accept(Id, New_id, Msg), and clone_reject(Id, New_id, Msg) are modeling an event that signals the existence of a new negotiation message of type propose, of type accept, and of type reject, respectively.

The particle clone_create(Id, New_id, Msg) models an event that signals the existence of a new negotiation message that announces creation of a new sequence for the current negotiation.

The particles message model the messages sent to allow their processing in terms of their interpretations in a typical negotiation process.

The particles message have the following parameters:

- Rname and New_r_name are identifiers of the sequence that generates the message and of a new sequence that is invited to negotiation, respectively.

- Content represents the content of the message which is a proposal regarding the negotiation task.

- Type represents an identifier of the new coordination policy that satisfies a certain pattern and that must be managed by the sequence invited to negotiation.

We propose four types of message particles: propose, accept, reject, and create. The particle propose(Rname, Content) signals the existence of a new proposal in the negotiation process, and the particles accept(Rname) and reject(Rname) signal the existence of an acceptance of a proposal and the existence of a denial of a proposal, respectively. The proposal to accept and, respectively, to deny was sent by a participant in the negotiation through the sequence Rname.

The particle create(New_r_name, Type) signals the existence of a new sequence that is part of the current negotiation phase and that is identified by New_r_name.

To properly formulate a coherent execution of a negotiation process, we introduced the control particles.

These particles have several functions in the computation space of a negotiation sequence:

- an identification function (e.g., name(Id)) that identifies the negotiation atoms by specifying an unique value to the parameter $I d$ for each atom. This unique value allows only to the specified atom to consume various events introduced in the system that are addressed to this atom;

- a limitation function (e.g., start(), enable(), freeze(), waiting()) that introduces the concept of control over the methods that may induce errors in negotiation. This type of particles limits the number of methods that may be executed in a given state. In this manner, we may establish a proper succession in the execution of certain methods. For example, we will use the particles enable and freeze to favour the methods to consume the events and to consume the messages, respectively. Through the aid of these two methods we will introduce a well-defined order in 
the negotiation process, first the creation of a negotiation atom and, second, the evolution of the negotiation phase in this newly created atom;

- a notification function (e.g., stop(Accord), ready (Accord)).

Description of the negotiation process

According to our approach regarding the negotiation, the participants to a negotiation may propose offers and each participant may decide in an autonomous manner to stop a negotiation either by accepting or by rejecting the offer received. Also, depending on its role in a negotiation, a participant may invite new participants to the negotiation. To model this type of negotiation, we will make use of the previously defined particles and we will propose the methods to manage the evolution of these particles. Through the use of the metaphor IAMs, the evolutions of the negotiation phases correspond to the evolutions at the atoms level. The evolution may be regarded as a process consisting of two stages: a cloning operation of the atom existent in the initial stage and a transformation operation within the cloned atom to allow for the new negotiation phase.

The cloning operation is expressed by a set of methods involving the particles event and these methods are used to facilitate the evolution of the negotiation. We propose the following methods associated to the particles event to model the cloning of an atom where new message particles are introduced:

- The method Propose is associated to the particle event clone_propose(Id, New_id, Msg) and models the introduction of a new proposal (clone_propose) by one of the participants to the negotiation. This method is expressed:

$$
\begin{aligned}
& \text { name }(I d) @ e n a b l e @ c l o n e \_p r o p o s e\left(I d, N e w \_i d, M s g\right) \\
& <>-(\text { enable @name }(I d)) \&\left(\text { freeze @ name }\left(N e w \_i d\right)\right. \\
& @ \operatorname{propose}(\text { Rname }, \text { Content }))
\end{aligned}
$$

The atom identified by the particle name(Id) is cloned. The new proposal contained in the particle propose (Rname, Content) will be introduced in the new atom name(New_id).

- The method Accept is associated to the event particle clone_accept(Id, New_id, Msg) and models the case when one of the participants sent a message indicating acceptance (clone_accept) of an older proposal. This method is expressed:

$$
\begin{aligned}
& \text { name }(I d) @ e n a b l e @ c l o n e \_a c c e p t\left(I d, N e w \_I d, M s g\right) \\
& <>-(\text { enable@name }(I d)) \&(\text { freeze @name }(\text { New_Id }) \\
& \text { @accept }(\text { Rname }))
\end{aligned}
$$

The atom identified by the name(Id) is cloned. The message to accept that is contained in the particle accept(Rname) will be introduced in the new atom name (New_id).

- The method Reject is associated to the event particle clone_reject(Id, New_id, Msg) and models the denial of an older proposal (clone_reject) made by one of the participants. This method is expressed:

$$
\begin{aligned}
& \text { name }(I d) @ e n a b l e @ c l o n e \_r e j e c t\left(I d, N e w \_I d, M s g\right) \\
& <>-(\text { enable@name }(I d)) \&\left(\text { freeze @name }\left(N e w \_I d\right)\right. \\
& \text { @reject }(\text { Rname }))
\end{aligned}
$$

The atom identified by the particle name $(I d)$ is cloned. The message of denial contained in the particle reject(Rname) will be introduced in the new atom name $\left(\mathrm{New}_{-} i d\right)$.

- The method Create is associated to the event particle clone_create(Id, New_id, Msg). This method models the invitation of a new sequence (clone_create) made by one of the participants toward the distribution of the newly created negotiation phase. This method is expressed:

$$
\begin{aligned}
& \text { name }(I d) @ \text { enable@clone_create }\left(I d, N e w \_I d, M s g\right) @ \\
& <>-(\text { enable@name }(I d)) \&\left(\text { freeze @name }\left(N e w \_I d\right)\right. \\
& \text { @create }(\text { Rname }, T y p e))
\end{aligned}
$$

The atom identified by the particle name(Id) is cloned and a particle create(Rname, Type) is introduced in the new atom name $\left(N_{e} w_{-} i d\right)$ that will subsequently generate a new representation particle for the new sequence that is participating to the negotiation.

The particles message participate to transformation methods that change the negotiation phase of an atom by replacing the representation particles of the negotiation sequences involved in the generation or in the receiving of the messages that are exchanged.

Next we propose the following transformation methods:

- The transformation method associated to the particle propose(Rname, Content) contributes to the local evolution of a negotiation phase regarding the status and the attributes negotiated. This evolution takes place by replacing, in the existing atom, all representation particles that are involved (depending on the method) with the new particles that have the status changed to undefined, and the set of the negotiated attributes (Issues) contains the new proposal expressed in the Content of the message particle.

\footnotetext{
freeze@localr(Rname1, S1, I1)@extr(Rname,S2, I1)

@ propose(Rname, Content)

$>$-enable@localr(Rname1, undefined, I)

@ extr(Rname, undefined, I)
} 
- The transformation method associated to a particle accept(Rname) leads to the local evolution of a negotiation phase regarding the status. The evolution is made by replacing, in the existing atom, the representation particles involved with the new particles whose status has been changed from initiated or undefined to success :

$$
\begin{aligned}
& \text { freeze@localr(Rname1, S1, I1) } \\
& \quad @ \text { extr(Rname,S2,I1) @accept(Rname) } \\
& <>-l o c a l r(\text { Rname1, success, I1) } \\
& \text { @extr(Rname, success, I1) }
\end{aligned}
$$

- The transformation method associated to a particle reject(Rname). This is similar to the method of particle accept(Rname), the distinction being that the evolution of the negotiation phase is made through modifying the status of the representation particles involved from initiated or undefined to failure:

$$
\begin{aligned}
& \text { freeze@localr(Rname1,S1,I1) } \\
& \text { @ extr(Rname, S2, I1) } \\
& \text { @ reject (Rname) <>-localr(Rname1, fail, I1) } \\
& \text { @ extr(Rname, fail, I1) }
\end{aligned}
$$

- The transformation method associated to a particle create(New_r_name, Type) contributes to the evolution of a negotiation phase regarding the number of the sequences that participate to this negotiation phase. This evolution is made by introducing in the corresponding atom a new representation particle:

$$
\begin{aligned}
& \text { freeze@create(Rname,type) } \\
& \quad<>- \text { extr(Rname, init, Ø) @enable }
\end{aligned}
$$

As soon as this sequence is invited to the negotiation, its status is initiated and its set of the negotiated attributes is the empty set.

The evolution of all negotiation atoms and the negotiation phases take place in parallel.

To model the coordination of the execution of the negotiation process perceived within a sequence, we used the communication mechanism among the existing negotiations. This type of particles that are part of the communication process among different negotiation atoms communicate to all negotiation atoms a certain result.

In the negotiation processes, the messages hold metainformation regarding the content of the messages that describe the proposals in terms of the value of different attributes of the negotiation object. To handle the negotiation proposals we use the concept of "raw" computation introduced within IAMs. We assume that each of the atoms implicitly contains in its state particles for processing different proposals in terms of mathematical operations or of strings manipulations.

\section{Methodology-based negotiation for sustainability of EI}

In the proposed scenario, a conflict occurs in a network of enterprises, threatening to jeopardize the interoperability of the entire system. The first step consists in identifying the Enterprise Interoperability issue. The following steps refer to analyse the problem, evaluate possible solutions and select the optimal solution. The proposed solution for conflict resolution is reaching a mutual agreement through negotiation. The benefit of this approach is the possibility to reach a much more stable solution, unanimously accepted, in a shorter period of time.

The design and coordination of the negotiation process must take into consideration:

- Timing (the time for the negotiation process will be preset);

- The set of participants to the negotiation process (which can be involved simultaneous in one or more bilateral negotiations);

- The set of simultaneous negotiations on the same negotiation object, which must follow a set of coordination policies/ rules;

- The set of coordination policies established by a certain participant and focused on a series of bilateral negotiations;

- Strategy/decision algorithm responsible for proposals creation;

- The common ontology, consisting of a set of definitions of the attributes used in negotiation.

The negotiation process begins when one of the enterprises initiate a negotiation proposal towards another enterprise, on a chosen negotiation object. We name this enterprise the Initiating Enterprise (E1). This enterprise also selects the negotiation partners and sets the negotiation conditions (for example sets the timing for the negotiation). The negotiation partners are represented by all enterprises on which the proposed change has an impact. We assume this information is available to E1 (if not, the first step would consist in a simple negotiation in which all enterprises are invited to participate at the negotiation of the identified solution. The enterprises which are impacted will accept the negotiation).

After the selection of invited enterprises (E2 ...En), E1 starts bilateral negotiations with each guest enterprise by sending of a first proposal. For all these bilateral negotiations, E1 sets a series of coordination policies/rules (setting the conditions for the mechanism of creation and acceptance of proposals) and a negotiation object/framework (NO/NF), 
setting the limits of solutions acceptable for E1. Similarly, invited enterprises set their own series of coordination policies and a negotiation object/framework for the ongoing negotiation.

After the first offer sent by E1, each invited enterprise has the possibility to accept, reject or send a counter offer. On each offer sent, participating enterprises, from E1 to E2 ...En follow the same algorithm:

Algorithm: Pseudo code representation of the negotiation process

Inputs: Enterprises E1 ...En

Outputs: The possible state of a negotiation: success, failure
This PIM may afterwards be transformed for each negotiation partner into its Platform-Specific Model (PSM) set of clouddeployed services.

By using Model-Driven Interoperability (MDI), a CIM model is created consisting on shared understanding regarding concepts, business models, semantic reasoning, and related aspects of the negotiating parties (e.g., agreed term meanings, negotiation behaviours), which is then transformed into a corresponding PIM where semantic ontologies are defined, and furthermore, to each negotiation partner's specific PSM databases and services (Jardim-Goncalves et al. 2010). This way, any interoperability change should be reflected in the corresponding model and thus be able to

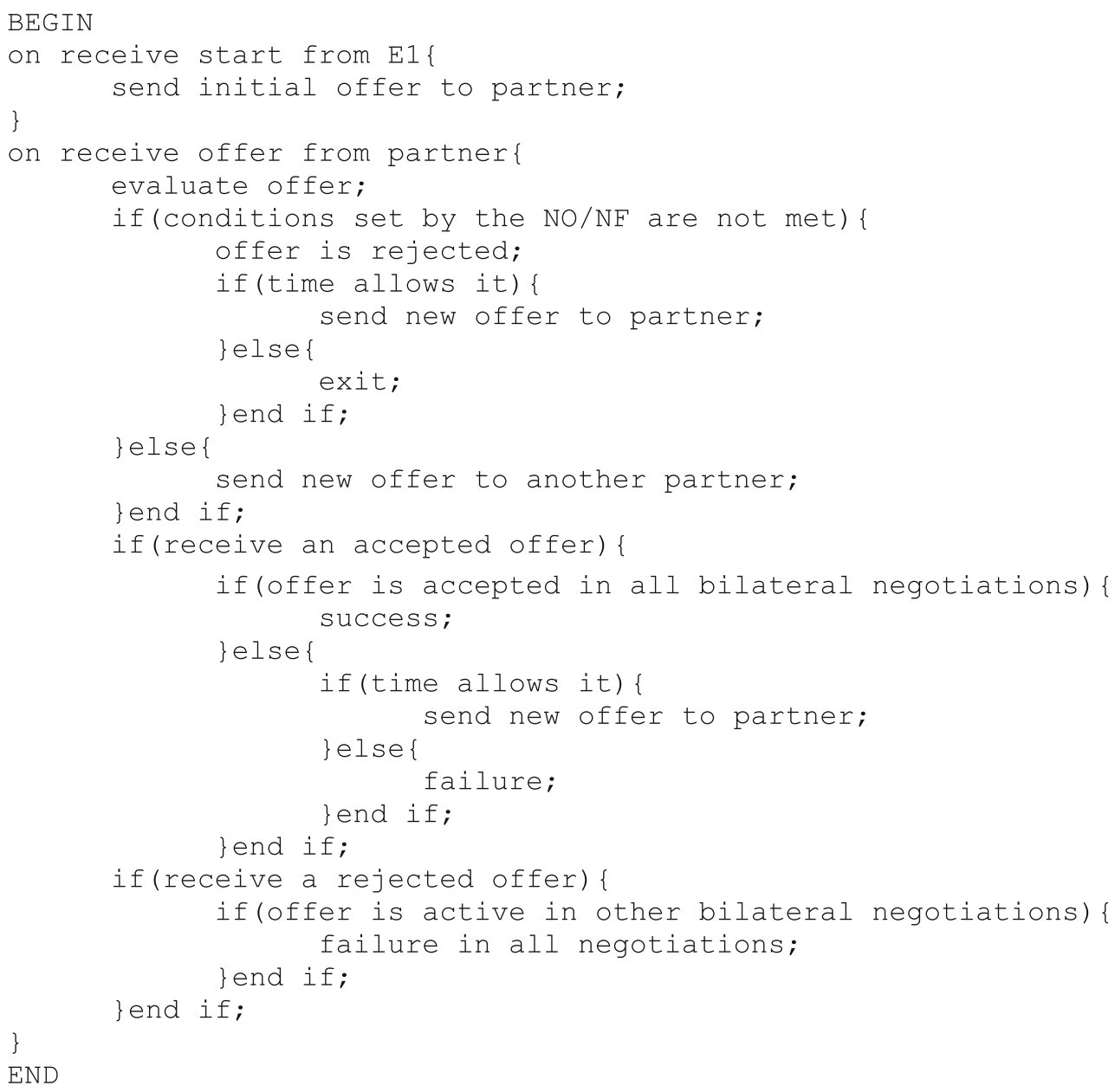

The proposed framework implements the foundations for $\mathrm{EI}$, relying on principles that allow interoperability to become reinforced. The first step is to model the basic foundations (services and infrastructure) of the framework in a MDA CIM which defines the negotiation concepts (e.g., the IAM states), then transform it into a Platform-Independent Model (PIM) to achieve a higher independence of external factors and to have a clear model of the negotiation partners' model. be assimilated by the other parties (Cretan et al. 2013), as represented on Fig. 2.

Figure 2 describes the architecture of the proposed framework for sustainability of EI. Sustainability here is stated in the sense of providing the interoperability environment means to be more robust and self-contained, relying more on transparency and knowledge than on assumptions and suppositions. The basic steps that support this sustainabil- 


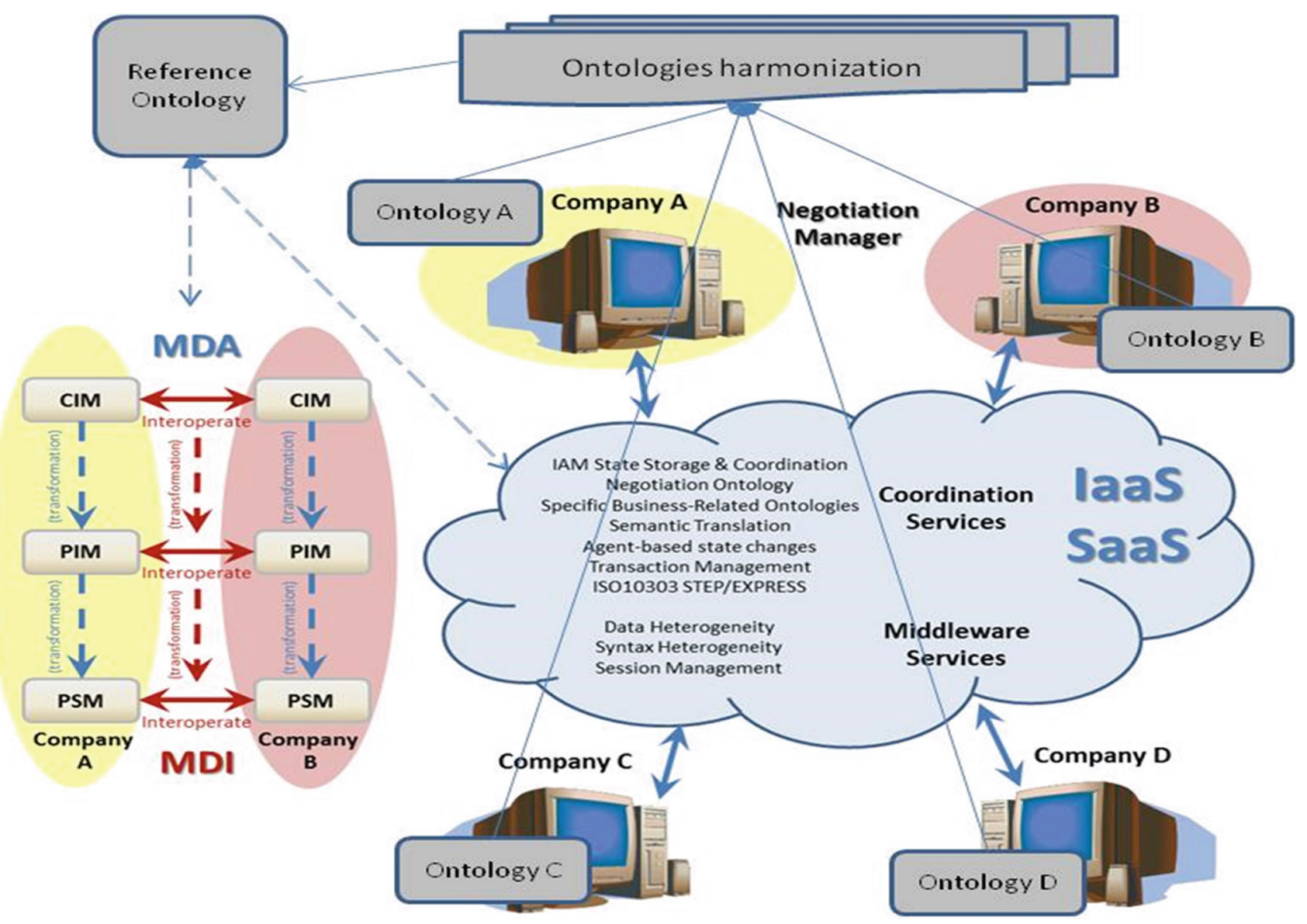

Fig. 2 The architecture of the framework for sustainability of EI

ity are a consistent model-driven development, together with the extensive usage of a reference ontology, resultant from the harmonisation of the concepts and relationships existing on the various entities intervenient on the business environment. In both of these basilar foundations for the proposed framework, there is an even more important concept that is transversal to the whole framework, which is negotiation. Negotiation, performed using the concepts defined on "Negotiation coordination model" section, models and shapes the MDI levels that are the fundaments for the interoperability in the business environment, and is used for the definition and refinement of the reference ontology. The modeldriven environment results into the definition of a set of services that implement the interoperable environment. The resulting infrastructure is hosted by a SaaS business paradigm, ensuring the handling of all heterogeneity issues (e.g., communications, syntax, session, data) of the basic Middleware level of the framework, on top of which a richer set of services (Coordination Services level) shall be built. These services perform complex activities like Transaction Management, the definition and management of the negotiation data model, storage and management of the negotiation data and business states which implement the model rules.
Regarding the information exchange, behaviour and other aspects of the interoperability itself, the proposed framework is built using the popular, simple, flexible and robust services in SOA. In order to manage the issues regarding size and scalability, the SOA platform for the framework is implemented on top of a cloud-based system.

Actually, data access, its models and data exchange can also be a problem for interoperability. Negotiation parameters, ontologies and other entities rely on data modelling, specification and consistency and therefore the best way to define the data models and the data exchange is to use a standard. In this case the selected solution is to model the data for databases and data access using the ISO10303 STEP and EXPRESS language specification, enriched by a proper reference ontology. The database infrastructure, as well as the whole model-driven framework infrastructure shall be implemented over cloud, using an IaaS platform.

\section{Business case scenario for framework validation}

This paper is being validated by its implementation in the scope of EU co-funded FP7 project TIMBUS (TIMBUS 


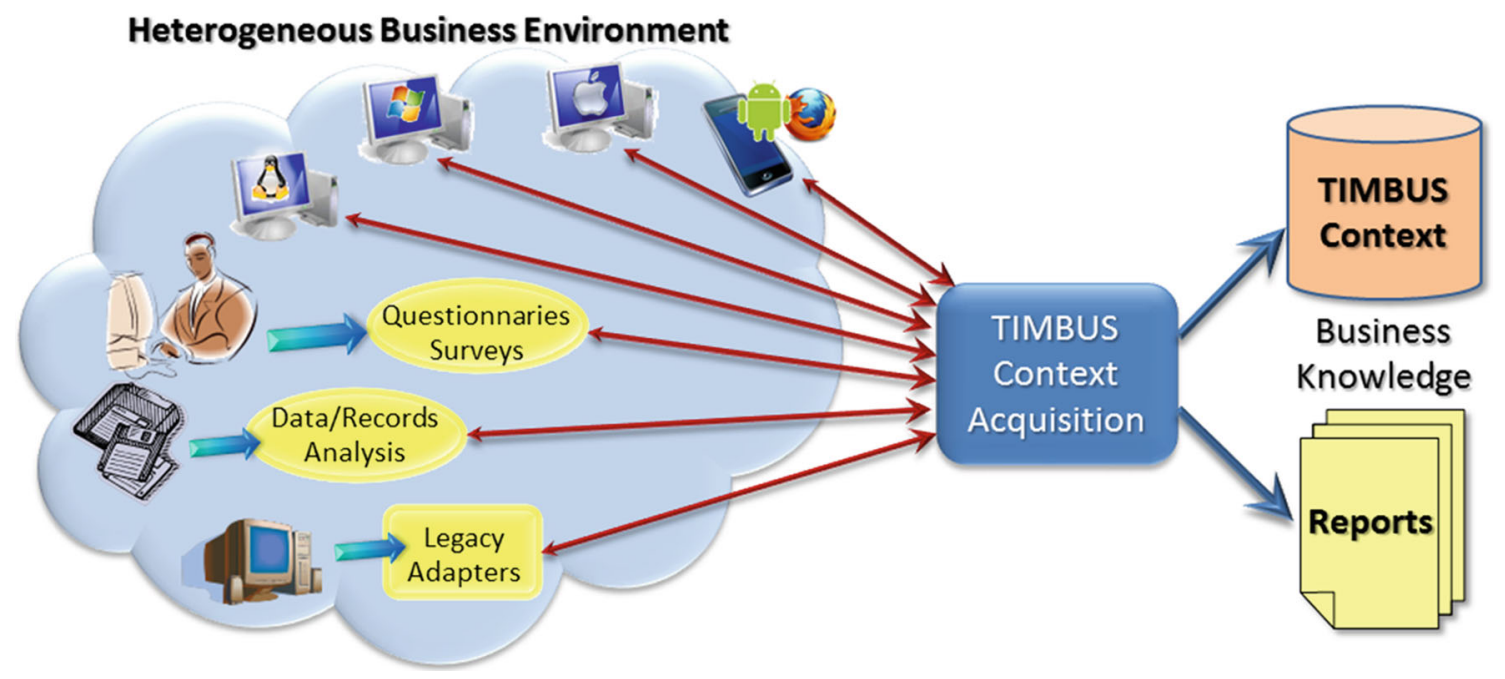

Fig. 3 Acquisition of business knowledge metadata

2013). TIMBUS stands for "Digital Preservation for Timeless Business Processes and Services", and focuses on having resilient business processes, based on metadata information stored in business ontologies. In order to maintain the business continuity of an enterprise, TIMBUS has the objective to ensure continued access to services and business assets, providing processes and methods for digitally preserving business processes. It includes a flexible and extensible software architecture, intelligent tools and technologies for performing the major functionalities of business and knowledge capturing, analysis and maintenance, preservation and storage of the information and meta-information, and future redeployment of the stored information to knowledge.

Digital Preservation, as an academic discipline and organisational practice aims to ensure the availability of information over a long period of time. It is essentially motivated by business and legal risks incurred by information loss or damage. On the other hand, Risk Management is traditionally addressed as a management discipline, performed typically in an isolated fashion within organisations, lacking the perspective on business processes. The proposed solution undertaken by the TIMBUS project extends the traditional digital preservation approaches as it introduces the need to analyse and sustain accessibility to business processes and the supporting services, aligning preservation actions with enterprise risk management (ERM) and business continuity management (BCM) activities.

The main innovation of TIMBUS project is therefore its focus on risk assessment based digital preservation of business processes, thus not only bringing together but also advancing traditional digital preservation, risk management and business process management disciplines. Preservation is often considered as a set of activities carried out in isolation within a single domain, without of taking into account the dependencies of third-party services, information and capabilities that will be necessary to validate digital information in the future. Existing DP solutions focus on more simple data objects which are static in nature. The unique aspect of TIMBUS is that it is attempting to advance state of the art by figuring out how more complex digital objects can be preserved and later restored in the same or different environments.

The proposed solution that is therefore based on two premises: Acquisition of business knowledge and risk management.

The initial step, Acquisition of business knowledge, concerns determining, capturing, modelling and indexing business knowledge into an information system, which is a very challenging task. The information model needs to be flexible enough to handle the heterogeneity in concepts and business information, able to comprise information from a business environment consisting in multiple systems, computers and other devices, people and other sources of information.

The proposed approach is to have an open architecture which is able to expand its ability to contact these information sources. In this sense it is able to retrieve information with more or less human intervention (i.e., although it is capable to access the information sources directly, it must be also able to receive information retrieved by other tools or by human intervention, this is relevant to handle some tricky security problems and to enhance confidence on the target systems). The proposed method is to develop generic extraction mechanisms, ones which are able to attach numerous specifically implemented extractors or adapters, which then are able to retrieve correctly the information. This information will then, in the scope of the same project, subject to risk analysis and treatment. 
Figure 3 shows the overall architecture of the Context Acquisition module, which works in a multi-agent system (MaS) paradigm, with dedicated and tailored agents extracting business metadata from the target environment. A central acquisition module gathers the inputs from the multiple agents running on heterogeneous operating systems, environments and platforms, legacy systems and records and business tacit knowledge captured by questionnaires and interviews, reasons these inputs, and models and stores the data into the information system.

The proposed organisation of the stored metadata is to store concepts and relationships into an ontology that properly consolidates this information, supported by a database to persist the remaining specific data. The schema for the central information system (known as Business Information Context) was defined and tailored in a modelling reference ontology, which was considered the best to capture all relevant aspects of an organization and its IT systems, considered the most proper way for storing the data and relating it to the ontology concepts.

As each business has its specificities, the ontologies are very diverse and are prone to several misinterpretations. To a particular business partner who is a furniture provider, the concept of a gate is totally different from a software provider, or from an electronics provider. Even in the same business, when defining concepts and requirements it is common to have slight differences in knowledge; this is where the proposed platform presents its added-value, enabling negotiation mechanisms and strategies to harmonise the ontologies representing business knowledge.

The project is being validated in multiple industrial business cases, like one for civil engineering dam management for the Portuguese National Laboratory for Civil Engineering (LNEC).

Business Context metadata is therefore captured by multiple sources (e.g., software agents, surveys and interviews, databases). However, this operation needs to reflect the continuous changes in the business environment, hence besides baselining the information capture, a module shall periodically (or on-demand) access the business environment, comparing the current state with the baselined metadata, and updating it into subsequent baselines.

Each of the retrieved concepts shall then need to be validated by the whole system, and this action frequently generates numerous conflicts, with multiple different semantic interpretations of the same concept, or different procedures and methods to define it. Negotiation in this scenario is then an essential tool to enable the central knowledge ontology to be developed. The proposed framework's need and applicability can then be validated by analysing a set of indicators, such as the amount of different terminologies and processes that need to be harmonised, the amount, effort and cost of the rework happening due to semantic mis- alignment before and after the application of the framework, the amount of time spent on harmonising these semantic issues with and without formal negotiation, the advantages in amount of time and cost of having a rich historic record of previous negotiations and negotiation steps and resulting outcomes.

The application of the proposed interoperability framework to TIMBUS used the negotiation strategies specified in the above proposed interoperability framework to allow each ontology element to be classified and related with the other ontology terms, thus contributing to the proper development of the project's reference ontology.

\section{Conclusions and future work}

This paper proposes an intelligent negotiation framework to manage parallel and concurrent negotiations in order to achieve and maintain the interoperability between the organisations' systems and applications by harmonising its related ontologies and knowledge through negotiation, and its validation in an industrial scenario developed under the Enterprise Information Systems concept. The adoption of cloudcomputing allows this procedure to be based on seamless services, accessible by everyone in any part of the network.

Currently, interoperability among the involved parties in a negotiation is often not reached or maintained due to failure in adapting to new requirements, parties or conditions. The use of an adaptive platform as proposed results in a seamless, sustainable interoperability, which favours its maintenance across time. The ability to reach and interoperate with more parties leads to new business opportunities and to stronger and healthier interactions. The sequence of this research shall comprise the completion of this framework with a contract management process and a renegotiation mechanism.

Acknowledgments The authors wish to acknowledge the support of the European Commission through the funding of the UNITE, MSEE, IMAGINE, and TIMBUS FP7 projects.

\section{References}

Agostinho, C., Correia, F., \& Jardim-Goncalves, R. (2011). Interoperability of complex business networks by language independent information models. In New world situation: New directions in concurrent engineering-Proceedings of the 17th ISPE international conference on concurrent engineering (CE 2010), Part 2 (pp. 111-124).

Ahmadi, K. D., \& Charkari, N. M. (2010). Multi agent based interactive recommendation and automated negotiation system in E-commerce. In 6th international conference on advanced information management and service (IMS) (pp. 279-284).

Ahmadi, K. D., Charkari, N. M., \& Enami, N. (2011). E-negotiation system based on intelligent agents in $\mathrm{B} 2 \mathrm{C}$ E-commerce. Advances on Information Sciences and Service Sciences, 3, 60-70.

Benaben, F., Boissel-Dallier, N., Pingaud, H., \& Lorre, J.-P. (2013). Semantic issues in model-driven management of information sys- 
tem interoperability. International Journal of Computer Integrated Manufacturing, 26(11), 1042-1053.

Benaben, F., \& Pingaud, H. (2010). The MISE Project: A first experience in mediation information system engineering. In A. D'Atri \& D. Saccà (Eds.), Information systems: People, organizations, institutions, and technologies (pp. 399-406). Heidelberg: Physica-Verlag HD. doi:10.1007/978-3-7908-2148-2_46.

Cao, M. (2012). Multi-strategy selection supported automated negotiation system based on BDI agent. In 45th Hawaii international conference on system sciences (pp. 638-647).

Chen, T.-Y., Chen, Y.-M., \& Cai, H.-Y. (2012). Design of knowledge trading negotiation model for accelerating acquirement of knowledge. International Journal of Computer Integrated Manufacturing, $25,1085-1101$.

Coutinho, C., Cretan, A., \& Jardim-Goncalves, R. (2012). Sustainable interoperability framework for supporting negotiation processes. In 6th international conference on interoperability for enterprise systems and applications (I-ESA 2012).

Cretan, A. (2011). A framework for supporting parallel and concurrent negotiations. In 1st UNITE doctoral symposium, Bucharest, Romania (pp. 140-146).

Cretan, A., Coutinho, C., Bratu, B., \& Jardim-Goncalves, R. (2012a). A framework for sustainable interoperability of negotiation processes. In 14th IFAC symposium on information control problems in manufacturing (INCOM'12).

Cretan, A., Coutinho, C., Bratu, B., \& Jardim-Goncalves, R. (2012b). NEGOSEIO: A framework for negotiations toward sustainable enterprise interoperability. Annual Reviews in Control, 36(2), 291-299. doi:10.1016/j.arcontrol.2012.09.010.

Cretan, A., Silva, C. F. da, Coutinho, C., Jardim-Goncalves, R., \& Ghodous, P. (2013). Framework for ontology-based negotiation to support enterprise interoperability in cloud-based environments. International Journal of Electronic Business Management, 11(3), $168-177$.

Dong, H., Hussain, F. K., \& Chang, E. (2008). State of the art in negotiation ontologies for multi-agent systems. International Journal of Web Services Practices, 3, 157-163.

Duan, L., Doğru, M. K., Özen, U., \& Beck, J. C. (2010). Multi-agent negotiation for distributed production scheduling problems. In $3 r d$ international workshop on agent-based complex automated negotiations.

Dutra, M., Ghodous, P., \& Kuhn, O. (2010). A generic and synchronous ontology-based architecture for collaborative design. Concurrent Engineering, 18, 65-74.

Emerson, E. A. (2010). Time of time. In 17th international symposium on static analysis, SAS 2010 (p. 1).

Georgantas, N., Ahaman, M. A., Ameziani, H., Pathak, A., \& Issarny, V. (2011). A coordination middleware for orchestrating heterogeneous distributed systems. In Lecture notes in computer science volume 6646: Advances in grid and pervasive computing (pp. 221-232).

Groléat, T., \& Pouyllau, H. (2011). Distributed inter-domain SLA negotiation using reinforcement learning. In The 12th IFIP/IEEE international symposium on integrated network management (IM) (pp. 33-40).

Haya, P. A., Montoro, G., Esquivel, A., García-Herranz, M., \& Alamán, X. (2006). A mechanism for solving conflicts in ambient intelligent environments. Journal of Universal Computer Science, 12, 284296.

Hu, J., \& Deng, L. (2011). An association rule-based bilateral multiissue negotiation model. In Fourth international symposium on computational intelligence and design (pp. 234-237).

Huan, F., \& Lili, W. (2010). Colored Petri net based multi-agents dynamic task allocation modeling and analysis. In The 2nd IEEE international conference on information science and engineering (ICISE) (pp. 1080-1083).
Izza, S. (2009). Integration of industrial information systems: From syntactic to semantic integration approaches. Enterprise Information Systems, 3, 1-57.

Jardim-Goncalves, R., Agostinho, C., Malo, P., \& Steiger-Garcao, A. (2007). Harmonising technologies in conceptual models representation. International Journal Of Product Lifecycle Management, 2, 187-205.

Jardim-Goncalves, R., Agostinho, C., \& Steiger-Garcao, A. (2010). Sustainable systems' interoperability: A reference model for seamless networked business. In 2010 IEEE international conference on systems, man, and cybernetics (SMC 2010) (pp. 1785-1792).

Jardim-Goncalves, R., Figay, N., \& Steiger-Garcao, A. (2006). Enabling interoperability of STEP Application Protocols at metadata and knowledge level. International Journal of Technology Management, $36,402-421$.

Jardim-Goncalves, R., Grilo, A., Agostinho, C., Lampathaki, F., \& Charalabidis, Y. (2012). Systematisation of interoperability body of knowledge: The foundation for enterprise interoperability as a science. Enterprise Information Systems, 6, 1-26.

Jazayeriy, H., Azmi-Murad, M., Sulaiman, N., \& Udzir, N. I. (2011). A review on soft computing techniques in automated negotiation. Scientific Research and Essays, 6, 5100-5106.

Jeon, P. B., Kim, J., Lee, S., Lee, C., \& Baik, D.-K. (2011). Semantic negotiation-based service framework in an M2M environment. In 2011 IEEE/WIC/ACM international conferences on web intelligence and intelligent agent technology (IEEE) (pp. 337-340).

Khattak, A. M., Pervez, Z., Latif, K., Sarkar, A. M. J., Lee, S., \& Lee, Y.-K. (2011). Reconciliation of ontology mappings to support robust service interoperability. In 2011 IEEE international conference on services computing (IEEE) (pp. 298-305).

Laclavík, M., Balogh, Z., Babík, M., \& Hluchý, L. (2006). AgentOWL: Semantic knowledge model and agent architecture. Computing and Informatics, 25, 421-439.

Li, M.-S., Cabral, R., Doumeingts, G., Popplewell, K. (2006). Enterprise interoperability research roadmap. 45 . http://cordis.europa.eu/ fp7/ict/enet/ei-research-roadmap_en.html.

Lin, R. J., \& Chou, S. T. (2003). Mediating a bilateral multi-issue negotiation. In The IEEE international conference on E-commerce (CEC 2003) (pp. 76-83).

Liu, Q., Cui, X., \& Hu, X. (2008). Conflict resolution within multi-agent system in collaborative design. In 2008 international conference on computer science and software engineering (IEEE) (pp. 520-523).

LNEC. http://www.Inec.pt/organizacao/dbb/nmmf/estudos_id. Accessed June 10, 2013.

Luo, X., Miao, C., Jennings, N. R., He, M., Shen, Z., \& Zhang, M. (2012). KEMNAD: A knowledge engineering methodology for negotiating agent development. Computational Intelligence, 28, 51105.

Mazuel, L., \& Sabouret, N. (2009). A communication protocol for semantic heterogeneity with incomplete ontology alignment. In Proceedings of the 8th international conference on autonomous agents and multiagent systems (AAMAS '09) (pp. 1187-1188).

Oliva, E., McBurney, P., Omicini, A., \& Viroli, M. (2010). Argumentation and artifacts for negotiation support. International Journal of Artificial Intelligence, 4, 90-117.

Oliveira, A. I., \& Camarinha-Matos, L. M. (2012). Electronic negotiation support environment in collaborative networks. Advances in Information and Communication Technology, 372/2012, 21-32.

Pan, L. (2011). Towards a framework for automated service negotiation in cloud computing. In The IEEE international conference on cloud computing and intelligence systems (CCIS2011) (pp. 364367).

Panetto, H. (2007). Towards a classification framework for interoperability of enterprise applications. International Journal of Computer Integrated Manufacturing, 20, 727-740. 
Panetto, H., \& Cecil, J. (2013). Information systems for enterprise integration, interoperability and networking: Theory and applications. Enterprise Information Systems, 7, 1-6.

Qing, G., \& Chun, C. (2003). An approach to solving deadlock in multiissue. In The IEEE international conference on information reuse and integration (IRI 2003) (pp. 48-52).

Relvas, A., Richardson, R., Coutinho, C., Ribeiro, A., \& Dunne, C. (2008). Domain design application (DDA) and enhancements of communication layer for CDF. In 3rd international workshop on system and concurrent engineering for space applications (SECESA 2008) (pp. 1-8).

Russ, C., \& Walz, A. (2012). MACSIMA: An agent framework for simulating the evolution of negotiation strategies in B2B-networked economies. In Lecture notes in business information processing (Vol. 98, pp. 191-218).

Sarraipa, J., Jardim-Goncalves, R., Gaspar, T., \& Steiger-Garcao, A. (2010a). Collaborative ontology building using qualitative information collection methods. In 5th IEEE international conference on intelligent systems (IS 2010) (pp. 61-66).

Sarraipa, J., Jardim-Goncalves, R., \& Steiger-Garcao, A. (2010b). MENTOR: An enabler for interoperable intelligent systems. International Journal of General Systems, 39, 557-573.

Sarraipa, J., Silva, J. P. M. A., Jardim-Goncalves, R., \& Monteiro, A. A. C. (2008). MENTOR-A methodology for enterprise reference ontology development. In 4th international IEEE conference on intelligent systems IS'08 (Vol. 1, pp. 32-40).

Shin, C., Dey, A. K., \& Woo, W. (2008). Mixed-initiative conflict resolution for context-aware applications. In Proceedings of the 10th international conference on ubiquitous computing (UbiComp '08) (pp. 262-271).

Shin, C., Dey, A. K., \& Woo, W. (2010). Toward combining automatic resolution with social mediation for resolving multiuser conflicts. Cybernetics and Systems, 41, 146-166.
Shin, C., Yoon, H., \& Woo, W. (2007). User-centric conflict management for media services using personal companions. ETRI Journal, 29, 311-321.

Sycara, K., \& Dai, T. (2010). Agent reasoning in negotiation. In D. M. Kilgour \& C. Eden (Eds.), Advances in group decision and negotiation volume 4: Handbook of group decision and negotiation (pp. 437-451). Berlin: Springer.

TIMBUS (2013). TIMBUS Project page. http://timbusproject.net. Accessed May 15, 2013.

Tolchinsky, P., Modgil, S., Atkinson, K., McBurney, P., \& Cortés, U. (2011). Deliberation dialogues for reasoning about safety critical actions. Autonomous Agents and Multi-Agent Systems, 25(2), 209259. doi:10.1007/s10458-011-9174-5.

Torres, J. M., \& Wijnands, Q. (2011). Distributed agents for multi-rover autonomy. In 20th international workshops on enabling technologies: Infrastructure for collaborative enterprises (pp. 53-58).

Wang, M., Wu, X., Zhang, W., Ding, F., Zhou, J., \& Pei, G. (2011a). A conceptual platform of SLA in cloud computing. In The 9th IEEE international conference on dependable, autonomic and secure computing (DASC2011) (IEEE) (pp. 1131-1135).

Wang, X. H., Wong, T. N., \& Wang, G. (2011b). Knowledge representation for multi-agent negotiations in virtual enterprises. International Journal of Production Research, 49, 4275-4297.

Yang, Z. C., Yang, S., Lei, Z. Q., Lin, Z. Y., \& Fei, W. Z. (2010). Research of the strategy in multi-issue negotiations deadlock. In The 2nd IEEE international conference on information engineering and computer science (ICIECS) (pp. 1-4).

Zdravković, M., Panetto, H., Trajanović, M., \& Aubry, A. (2011). An approach for formalizing the supply chain operations. Enterprise Information Systems, 5, 401-421. 